http://dx.doi.org/10.11646/zootaxa.3681.4.5

http://zoobank.org/urn:lsid:zoobank.org:pub:F68AE86E-29A9-47D3-89F6-2B98FD90B68A

\title{
A New Genus of Highly Specialized Ants in Cretaceous Burmese Amber (Hymenoptera: Formicidae)
}

\author{
PHILLIP BARDEN \& DAVID GRIMALDI \\ Division of Invertebrate Zoology and Richard Gilder Graduate School, American Museum of Natural History, New York, New York \\ 10024-5192.E-mail: pbarden@amnh.org, grimaldi@amnh.org
}

\begin{abstract}
A new genus of ants, Zigrasimecia Barden and Grimaldi, is described for a new and uniquely specialized species, Z. tonsora Barden and Grimaldi n.sp., preserved in Cretaceous amber from Myanmar. The amber is radiometrically dated at 99 myo. Zigrasimecia is closely related to another basal genus of ants known only in Burmese and French Cretaceous amber, Sphecomyrmodes Engel and Grimaldi, based in part on the shared possession of a comb of pegs on the clypeal margin, as well as mandible structure. Highly specialized features of Zigrasimecia include extensive development of the clypeal comb, a thick brush of setae on the oral surface of the mandibles and on the labrum, and a head that is broad, flattened, and which bears a crown of blackened, rugose cuticle. Mouthparts are hypothesized to have functioned in a unique manner, showing no clear signs of dentition representative of "chewing" or otherwise processing solid food. Although all ants in Burmese amber are basal, stem-group taxa, there is an unexpected diversity of mouthpart morphologies and probable feeding modes.
\end{abstract}

Key words: Myanmar, Aptian-Cenomanian boundary, mouthparts, feeding behaviors, ants

\section{Introduction}

Among the nearly 13000 species of described ants are a handful of rare and enigmatic taxa from the Cretaceous. While molecular-clock dating analyses suggest that crown-group ants diverged from their wasp-like ancestors between 115-135 (Brady et al. 2006) and 140-168 million years ago (Moreau et al. 2006), the oldest definitive ant fossils are approximately 100 myo, despite numerous older insect-yielding deposits (Nel et al. 2004). In amber deposits where ants are found, formicid inclusions from the Upper Cretaceous comprise between $<1$ and $3 \%$ of the total number of individual insects (LaPolla et al. 2013), a palpable contrast to much younger Miocene deposits where ant prevalence is as high as 24-36\% (Grimaldi and Engel 2005; Dlussky and Rasnitsyn 2007). While younger amber deposits typically contain species that are readily placed in extant lineages (Dlussky and Rasnitsyn 2003), only one species of crown-group ant (a formicine) has been definitively identified before the Campanian (Grimaldi and Agosti 2000). The rest of the, proposed stem-group, Cretaceous taxa possess an array of unique morphologies that renders them unrecognizable with regard to modern groups and their relationship to living species is poorly explored. Ants from the Upper Cretaceous therefore act as valuable portholes, providing otherwise unknowable details at a critical time in the history of these small insects that now dominate terrestrial environments across the world.

Fossil ants are typically identified on the basis of key diagnostic characters such as the metapleural gland, petiole, and an enlarged antennal scape. While the possession of one individual character does not imply that the insect in question is indeed a member of crown-group or stem-group ants, different combinations of the presence and absence among these characters have been the basis for taxonomic assignment. The metapleural gland, visible as a small opening on the posterior region of the mesosoma, is now known to function as a form of toxic defense and sanitation (Yek and Mueller 2011). Although it has been lost in many extant species, it is not present in any other groups of insects, and therefore is probably the most reliable defining character of ants. The vast majority of Cretaceous ants have been placed in the extinct subfamily Sphecomyrminae, their placement owing largely to this 
gland. Sphecomyrmine ants possess a metapleural gland, along with a petiole, but not the characteristic "elbowed antennae" that modern ants exhibit and so this subfamily is widely recognized as a stem-group of all other Formicidae (e.g., Ward 2007). Sphecomyrminae currently contains 8 genera and 15 species (LaPolla et al. 2013), and, while there is no phylogenetic evidence to suggest the subfamily is monophyletic, one analysis has shown it may be a member of the group that is sister to all modern ants (Grimaldi et al. 1997).

Burmese amber is dated at $~ 99$ mya (Shi et al. 2012) and, along with slightly older Charentese amber from France (Nel et al. 2004), is one of the two oldest ant-yielding ambers. Inclusions from Myanmar have, however, provided unique insight into ant evolution in the form of six highly disparate species (Table 1). At present, the authors are aware of over 30 unstudied specimens from this deposit. Each clearly preserved specimen from Burmese amber has been placed within the Sphecomyrminae, with two presently incertae sedis species. Among these taxa are three species, each within the genus Haidomyrmex, that possess dramatic, scythe-shaped mandibles, which presumably acted in a trap-jaw fashion (Dlussky 1996; Barden and Grimaldi 2012). In addition, ants with similar mandibular shape are known from French Charentese amber (Perrichot et al. 2008) and Campanian-aged amber from western Canada (McKellar et al. 2013), demonstrating that specialized feeding morphologies were widespread during this time period-presumably a result of adaptive success. Here, we present yet another ant specimen with cranial morphology not before seen in any ant species, living or extinct.

TABLE 1. Summary of all ants described from Burmese amber.

\begin{tabular}{|c|c|c|c|}
\hline Species & Subfamily & Caste & Salient Details \\
\hline Burmomyrma rossi & $\begin{array}{l}\text { Incertae sedis: } \\
\text { possible Aneuretinae } \\
\text { or Sphecomyrminae }\end{array}$ & Alate female & $\begin{array}{l}\text { No head, not possible to identify with other } \\
\text { sphecomyrmine ants (Dlussky 1996) }\end{array}$ \\
\hline Haidomyrmex cerberus & Sphecomyrminae & Wingless female & $\begin{array}{l}\text { Probable trapjaw-ant, curved mandibles, setae } \\
\text { coated clypeus (Dlussky 1996) }\end{array}$ \\
\hline Haidomyrmex scimitarus & Sphecomyrminae & Dealate female & $\begin{array}{l}\text { Similar to H. cerberus, larger, parallel mandibles } \\
\text { (Barden and Grimaldi 2012) }\end{array}$ \\
\hline Haidomyrmex zigrasi & Sphecomyrminae & Wingless female & $\begin{array}{l}\text { Similar to } H \text {. cerberus, mandibles parallel at tips } \\
\text { (Barden and Grimaldi 2012) }\end{array}$ \\
\hline Myanmyrma gracilis & $\begin{array}{l}\text { Incertae sedis: } \\
\text { possible ponerine }\end{array}$ & Wingless female & $\begin{array}{l}\text { Gracile bodyform. Long pincher-like mandibles, } \\
\text { incised clypeus with clypeal spicules (Engel and } \\
\text { Grimaldi 2005) }\end{array}$ \\
\hline Sphecomyrmodes orientalis & Sphecomyrminae & Wingless female & $\begin{array}{l}\text { Most similar in form and mandible structure to } \\
\text { modern ants. Clypeus possess spicules (Engel } \\
\text { and Grimaldi 2005) }\end{array}$ \\
\hline
\end{tabular}

\section{Methods and materials}

The unique specimen is in Burmese amber, which derives from the northern state of Kachin, specifically $100 \mathrm{~km}$ west of the town of Myitkyina (Grimaldi et al., 2002). Samples of amber matrix from these outcrops were radiometrically dated at 99 myo, using U-Pb isotopes (Shi et al., 2012). This places the age of the deposit very close to the Aptian-Cenomanian boundary, which is also the boundary of the Early and Late Cretaceous. The amber piece containing the ant was originally a large $(20 \times 40 \mathrm{~mm})$, drop-shaped piece, which was trimmed and ground to $6 \times 7 \times 4 \mathrm{~mm}$ to maximize close views of the lateral and dorsal surfaces of the body and a frontal view of the head. Trimming used a water-fed, diamond-edged trim saw (4 in diameter, $1 \mathrm{~mm}$ thickness); grinding and polishing used a series of decreasing grits $(400,600,800,1200,2400)$ of emory papers on a water-fed lapidary wheel. For observation the small cube of amber was pressed lightly into a small piece of dental wax affixed to a microscope slide, and oriented in various positions to maximize views of various structures. Lighting used transmitted and reflected fiber optic illumination; examination, measurement, and drawing (with drawing tubes) was done with a Leitz Wetzlar and Wild M-1 stereoscope and a Wild compound scope. 


\section{Systematics}

\section{Zigrasimecia Barden And Grimaldi, new genus}

Diagnosis, gyne: Based on unique dealate specimen. Similar to Sphecomyrmodes based on structure of the mandible (with only two large teeth: one apical, one subapical); ocelli large, scape very short (slightly less than twice the length of pedicel), 12 antennomeres, eyes relatively small, and clypeal margin with row of peg-like denticles. Differs from Sphecomyrmodes by the flattened, broad head with irregular posterodorsal margin; very broad, concave clypeal margin with many more (ca. 30) denticles, plus two shorter rows of denticles ventrally; mandibles about half the length, with dense brush of spicule-like setae on oral surface; setae-coated labrum; presence of raised toruli and shallow lateral antennal scrobes; vertex of head with pair of oval, melanized, rugose patches.

Type species. Z. tonsora, new species.

Etymology. Patronym, for Mr. James Zigras, and -mecia, a common suffix for ant genera. In acknowledgment of Mr. Zigras' generosity in loaning this and many other rare and scientifically valuable specimens from his collection of Burmese amber.

\section{Zigrasimecia tonsora, Barden and Grimaldi, new species}

Figs. 1-2

Diagnosis, gyne: As for genus.

Description. All numbers in millimeters (mm). HEAD: Broad and flattened; head depth (length) (vertex to clypeal margin, excluding clypeal denticles) 0.66 ; head width (excluding eyes) 0.76 (1.38x that of mesosoma); distance between inner margins of eyes 0.65 , greatest thickness (dorsoventrally) 0.52 . Apparently prognathous, with cervical connection near vertex of head. Occipital (posterodorsal) margin of head irregular in dorsal view, slightly emarginate. Postocciput concave. Eyes small, protruding, slightly drop-shaped in lateral view (posterior end narrowed); length 0.21 , greatest width 0.13 , located on posterior half of head. Ocelli large, diameter 0.06. Vertex with pair of oval-shaped, melanized patches of rugose cuticle. Dorsofrontal portion of head with very fine, sparse setulae. Gena protruding, with apex narrow and extended well past level of clypeal denticles. Frons with dorsoventral portion having very shallow V-shaped groove that meets medially and extends over antennal bases. Frontal carinae absent. Base of antenna obscured by protruding toruli; antennal bases projected laterad from underneath toruli; distance between inner margins of antennae 0.25 ( $1 / 3$ width of head). Very shallow antennal scrobes present projecting outward laterally from bases of antennae to ventral margin of eyes. Antenna with 12 antennomeres (10 flagellomeres); scape very short, 0.22 length; pedicel 0.13; flagellomeres I-X: 0.17, 0.14, 0.095, $0.095,0.10,0.10,0.09,0.08,0.085,0.14$, respectively. Total length of antenna 1.42. Clypeus shallow, length (depth) 0.10 (excluding denticles); broad, distance between lateral-most denticles 0.44 ; significantly concave in shape (vs. straight). Oral margin of clypeus entirely lined with row of 30 denticles; denticles peg-shaped, with rounded apices, lengths ca. $4 \times$ the width. Ventral to row of clypeal margin denticles are two shorter rows of denticles, with approximately 15 denticles in each row. Mandibles short, barely overlapping medially, approximate length 0.345 ; dentition very simple, with one large apical tooth and large subapical tooth, masticatory margin otherwise devoid of teeth; outside surface of mandible slightly concave; oral surface of mandible with dense brush of stiff, sharp, spicule-like setae. Labrum coated in numerous setae, longer and more narrow than those found on clypeus. Palps short; maxillary palp with 5 segments, total length 0.23 (labial palp mostly obscured).

MESOSOMA: Depth (greatest dorso-ventral distance) 0.60, length (including neck) 1.40; greatest width of mesosoma 0.55 ;. With sparse, very fine, erect setae on dorsal surfaces (setae slightly recurved on propodeum). Neck long, nearly $1 / 4$ the length of true thorax (i.e., mesosoma not including propodeum). Two incomplete, Vshaped sulci present on dorsomedial portion of pronotum. Promesonotal suture complete, extremely well developed. Mesoscutum and mesoscutellum fully demarcated by sulcus; scutellum nearly $1 / 2$ length of scutum (length of mesoscutum 0.44, mesoscutellum 0.23); dorsal surface of scutellum with pair of deep, rectangular foveae close to median line. Dorsellum well developed, visible dorsally, with pair of shallow foveae dorsolaterally. Laterally: pronotum well developed, without foveae and very few setae; mesopleuron fully separated from the rest 


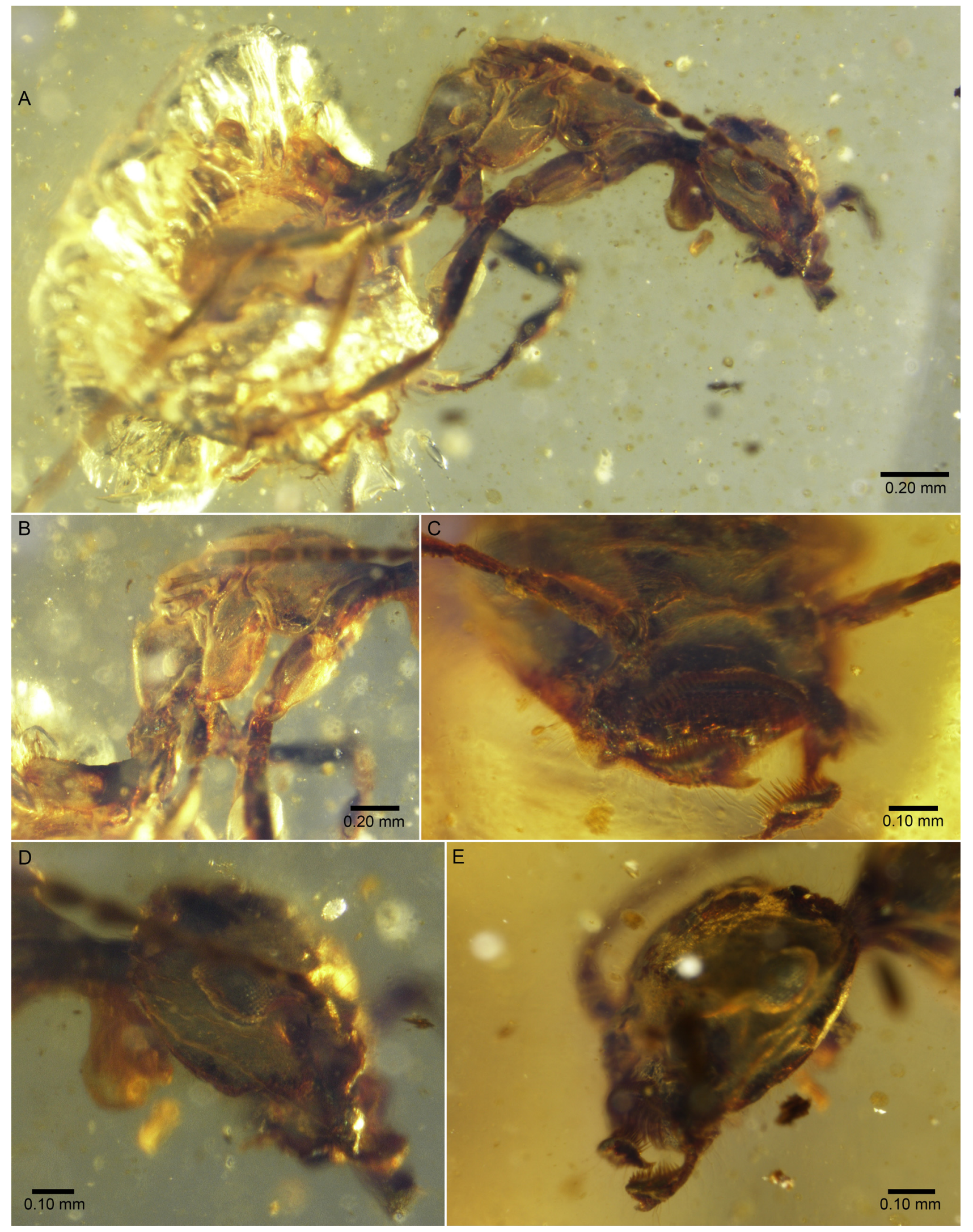

FIGURE 1. Zigrasimecia tonsora photomicrographs. (A) Lateral view of entire specimen. (B) Close-up image of mesosoma. (C) Enlarged view of clypeal and mandibular structures. (D) Right lateral view of Head. (E) Alternate left lateral view of head. 


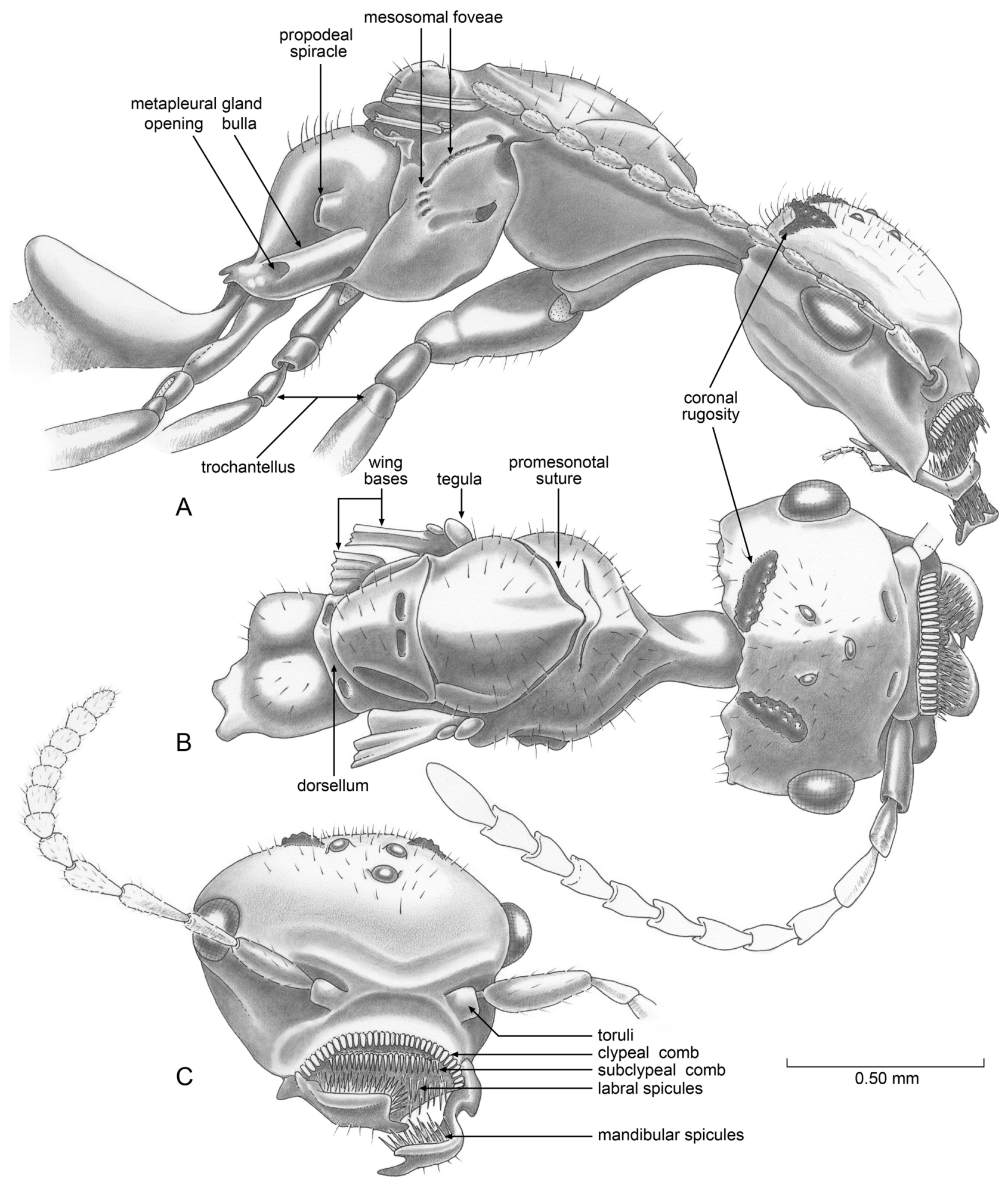

FIGURE 2. Drawings of holotype of Zigrasimecia tonsora, as preserved. (A) Head, mesosoma, and petiole, right lateral view. (B) Head and mesosoma, dorsal view. (C) Head, frontal view.

of the mesosoma by complete sulci, dorsally bearing C-shaped series of grooves and foveae. Propodeum deep, (depth 0.40); greatest [oblique] length 0.55 ; declivity steep (in lateral view ca. $65^{\circ}$ from horizontal); propodeal spiracle slit-like, facing posteriad, situated on raised base; posterior margin of propodeum shelf-like, with median 
emargination. Metapleural gland opening large, crescent-shaped; metapleural bulla well developed, hemicylindrical. Petiole deep (depth 0.40), lateral thickness ca. 0.15 [difficult to observe - petiole appears adpressed to anterior wall of metasoma, but most of metasoma obscured by layer of air). Legs: Trochantellus present on all legs, very well separated from trochanter and femur on meso- and metathoracic legs. Claws with large, subapical tooth on ventral margin.

METASOMA: Mostly obscured, apparently large; sting present [best seen ventrally in view from front].

Type: Holotype, JZC Bu-159, dealate female. Myanmar: Kachin State, near Myitkyina, formed near the Aptian-Cenomanian (Early Cretaceous - Late Cretaceous) boundary (Shi et al., 2012). In James Zigras Collection, available for study through the American Museum of Natural History. The ant is preserved in relatively clear, deep yellow amber; the metasoma is encased within a bubble that obscures most of it.

Etymology. "barber-mouthed," based on tonsor, barber, hairdresser (L., masculine); and oris, mouth (L.); in reference to the mouthparts bearing combs and brushes.

\section{Discussion}

The relationship between fossil stem-group ants and their modern counterparts has never been robustly tested in a phylogenetic context outside of limited datasets (Grimaldi et al. 1997) and usage as outgroup taxa (Ward and Brady 2003). A recent morphological study has provided insight into the mouthparts of basal extant ants (Keller 2011), and, while this is a valuable resource, placing Cretaceous taxa remains a difficult process. Still, it is possible to attempt to place Zigrasimecia tonsora using key synapomorphies: specifically the metapleural gland, scape length, and petiole are as in Bolton's (2003) diagnosis for the subfamily Sphecomyrminae. While Z. tonsora exhibits a number of autapomorphies not seen in other ants, such as mandibular structure and mesosomal sculpturing, this subfamily placement most closely reflects the morphology of the described animal at present. It should be noted that the status of the subfamily Sphecomyrminae has been evaluated using phylogenetic methodology only once (Grimaldi et al. 1997), and therefore it is possible that the subfamily may not in fact be monophyletic. Further, without a clear consensus on what synapomophy or combination thereof (i.e. metapleural gland + petiole, elongated scape + petiole, etc) differentiates stem-group and crown-group ants, distinction between the two may become confused. The authors suggest any aculeate possessing a metapleural gland and petiole is an ant however, the metapleural gland has been lost in some highly subordinate taxa.

Some apomorphic characters indicate that $Z$. tonsora has a close relationship with the extinct genera Sphecomyrmodes (Engel and Grimaldi 2005; Perrichot et al. 2008) and Gerontoformica (Nel et al. 2004). Perhaps the most significant character is the presence of peg-like setae around the oral cavity. Indeed $S$. orientalis Engel and Grimaldi, S. occidentalis Perrichot et al., and G. cretacica Nel et al. each possess a single row of stout setae along the entire anterior margin of the clypeus. While Z. tonsora exhibits two additional rows of these setae, the structures are not seen in any other described Cretaceous ants. Along with clypeal pegs, G. cretacica also possesses teeth-like setae on the labrum and, although the Z. tonsora labral setae are more tapered and hair-like, the similarity is noteworthy. In addition, S. occidentalis from French amber and Z. tonsora possess ocelli that are similar in form and position. Ocelli are not present in G. cretacica and not known from S. orientalis because the dorsal region of the head is obscured. While there are similarities between $Z$. tonsora, the two members of Sphecomyrmodes, and Gerontoformica, it is highly unlikely that they are different castes of the same species, $Z$. tonsora being a dealate female. The mandibular structure, coronal rugosity, and mesosomal sculpturing is significantly different (and gynes actually tend to be similar, if not less specialized compared to workers). At least in the case of Haidomyrmodes mammathus from Cretaceous French amber (Perrichot et al. 2008), worker and dealate castes are morphologically very similar.

The unique morphology of $Z$. tonsora is certainly perplexing and likely is representative of habits that are not seen in modern ants. The prognathous but apparently highly movable head (Fig 1.B. evidenced by the elongate, necklike pronotum) suggests that head mobility was important, perhaps related to feeding behavior. Another possibility is that the rugose projections (Figs 1A-B, Fig 2 E) on the head may have aided in nest excavation, as the very specialized setae-coated mandibles likely would have prohibited those efforts. There is no evidence for nesting behavior in Cretaceous ants, however it would be plausible that a dealate queen would need a means for creating a nest, alternative explanations are evasive. 
The mandibles themselves possess almost no fine dentition but are covered in stiff, sharp setae of variable length. It seems possible that this extensive setose covering is likely to have functioned in conjunction with the setae present elsewhere around the oral cavity. Both the clypeus and labrum are uniformly covered with short peglike setal projections and longer, sharper setae, respectively. Similar structures are found on the labrum of ants in the genera Apomyrma (Brown et al. 1971) and Opomyrma (Yamane et al. 2008) and clypeus of some members of the genera Amblyopone, Adetomyrma, Stigmatomma, and Martialis (Rabeling et al. 2008; Ward 1994; Yoshimura and Fisher 2012; www.antweb.org). It is interesting to note that numerous basal taxa exhibit these setae patterns, some along with a prognathous head shape. This convergence may be an indication that these morphologies are of particular importance to early ant evolution and intensive study of extant setae function may provide insight into how Cretaceous ants utilized these unique structures.

In extant formicids, the function of oral setae is not entirely clear, other than the long sensory trigger hairs found in trapjaw ants such as Odontomachus and Anochetus. In Z. tonsora, these structures are unlikely to have acted as trigger-hairs as they are much shorter and stout, perhaps indicating a use more in line with mechanical interaction with food items. There are ants today that feed on honeydew or hemolymph (Hölldobler and Wilson 1990; Saux et al. 2004). Perhaps the hydrophobic nature of some insect setae may have allowed for the manipulation of liquid food items such as these. Another possibility is that the unification of mandibles with the clypeal and labral setae would have acted as kind of trap for tiny arthropods such as mites or small flies.

It is difficult to comment on functional morphology beyond the realm of speculation, however it is clear that the cranial morphology of $Z$. tonsora is highly specialized. This new specimen echoes a surprising theme among Cretaceous ants: feeding behaviors were very diverse, and produced morphologies unlike those found in modern day insects. The present discovery marks an additional ant with mouthparts unlike those found in extant species, adding to those found in Burmese, French, New Jersey, and Canadian amber deposits. The gradual unearthing of these unique morphologies underscores the need for a robust phylogenetic analysis that accounts for all ant diversity, present and past.

\section{Acknowledgments}

We are grateful for the loan of the unique specimen by James Zigras, and for his continued generosity in loaning specimens from his collection; to Brian Fisher for insight into clypeal and labral setae structures; Steve Thurston, for assistance with figures; and two anonymous reviewers for valuable feedback. Financial support from National Science Foundation Predoctoral and Richard Gilder Graduate School fellowships.

\section{References}

Antweb (2013) Available from: http://www.antweb.org (Accessed 1 January 2013)

Barden, P. \& Grimaldi, D. (2012) Rediscovery of the bizarre Cretaceous ant Haidomyrmex Dlussky (Hymenoptera: Formicidae), with two new species. American Museum Novitiates, 3755, 1-16. http://dx.doi.org/10.1206/3755.2

Bolton, B. (2003) Synopsis and classification of Formicidae. Memoirs of the American Entomological Institute, 71, 1-370.

Brady, S.G., Schultz, T.R., Fisher, B.L. \& Ward, P.S. (2006) Evaluating alternative hypotheses for the early evolution and diversification of ants. Proceedings of the National Academy of Sciences, 103(48), 18172-18177.

Brown, W.L., Jr., Gotwaldm W.H. Jr., \& Levieux, J. (1971) A new genus of ponerine ants from West Africa (Hymenoptera: Formicidae) with ecological notes. Psyche, 77, 259-275. http://dx.doi.org/10.1155/1970/64703

Dlussky, G.M. (1996) Ants (Hymenoptera: Formicidae) from Burmese amber. Paleontological Journal, 30(4), $449-454$.

Dlussky, G.M. \& Rasnitsyn, A.P. (2003) Ants (Hymenoptera: Formicidae) of Formation Green River and some other Middle Eocene deposits of North America. Russian Entomological Journal, 11, 411-436.

Dlussky, G.M. \& Rasnitsyn, A.P. (2007) Paleontological record and stages of ant evolution. Uspehi Sovremennoi Biologii, 127, 118-34.

Engel, M.S. \& Grimaldi, D.A. (2005) Primitive new ants in Cretaceous amber from Myanmar, New Jersey, and Canada (Hymenoptera, Formicidae). American Museum Novitates, 3485, 1-23.

http://dx.doi.org/10.1206/0003-0082(2005)485[0001:PNAICA]2.0.CO;2 
Grimaldi, D., Agosti, D. \& Carpenter, J.M. (1997) New and rediscovered primitive ants (Hymenoptera: Formicidae) in Cretaceous amber from New Jersey, and their phylogenetic relationships. American Museum Novitates, 3208, 1-43.

Grimaldi, D. \& Agosti, D. (2000) A formicine in New Jersey Cretaceous amber (Hymenoptera: Formicidae) and early evolution of the ants. Proceedings of the National Academy of Sciences, 97, 13678-83. http://dx.doi.org/10.1073/pnas.240452097

Grimaldi, D., Engel, M.S. \& Nascimbene, P. (2002) Fossiliferous Cretaceous amber from Burma (Myanmar): its rediscovery, biotic diversity, and paleontological significance. American Museum Novitates, 3361, 1-71. http://dx.doi.org/10.1206/0003-0082(2002)361\%3C0001:FCAFMB\%3E2.0.CO;2

Grimaldi, D.A. \& Engel, M.S. (2005) Evolution of the Insects. Cambridge University Press, New York. 755 pp.

Hölldobler, B. \& Wilson, E.O. (1990) The Ants. Harvard University Press, Cambridge. 630 pp.

Keller, R.A. (2011) A phylogenetic analysis of ant morphology (Hymenoptera: Formicidae) with special reference to the poneromorph subfamilies. Bulletin of the American Museum of Natural History, 355, 1-90. http://dx.doi.org/10.1206/355.1

LaPolla, J.S., Dlussky, G.M. \& Perrichot, V. (2013) Ants and the Fossil Record. The Annual Review of Entomology, 58, 609-30. http://dx.doi.org/10.1146/annurev-ento-120710-100600

McKellar, R.C., Glasier, J. \& Engel, M.S. (2013) A new trap-jawed ant (Hymenoptera: Formicidae: Haidomyrmecini) from Canadian Late Cretaceous Amber. The Canadian Entomlogist, 12. http://dx.doi.org/10.4039/tce.2013.23

Moreau, C.S., Bell, C.D., Vila, R., Archibald, S.B. \& Pierce, N.E. (2006) Phylogeny of the ants: diversification in the age of angiosperms. Science, 312, 101-104. http://dx.doi.org/10.1126/science.1124891

Nel, A., Perrault, G., Perrichot, V. \& Neraudeau, D. (2004) The oldest ant in the Lower Cretaceous amber of Charente-Maritime (SW France) (Insecta: Hymenoptera: Formicidae). Geologica Acta, 2, $23-29$.

Perrichot, V., Nel, A., Neraudeau, D., Lacau, S. \& Guyot, T. (2008) New fossil ants in French Cretaceous amber (Hymenoptera: Formicidae). Naturwissenschaften, 95, 91-97. http://dx.doi.org/10.1007/s00114-007-0302-7

Poinar, G.O. Jr, Archibald, B. \& Brown, A. (1999) New amber deposit provides evidence of Early Paleogene extinctions, paleoclimates and past distributions. The Canadian Entomologist, 131, 171-77. http://dx.doi.org/10.4039/Ent131171-2

Rabeling, C., Brown, J.M. \& Verhaagh, M. (2008) Newly discovered sister lineage sheds light on early ant evolution. Proceedings of the National Academy of Sciences, 105(39), 14913-17. http://dx.doi.org/10.1073/pnas.0806187105

Saux, C., Fisher, B. \& Spicer, G.S. (2004) Dracula ant phylogeny as inferred by nuclear 28S rDNA sequences and implications for ant systematics (Hymenoptera: Formicidae: Amblyoponinae). Molecular Phylogenetics and Evolution, 33, 457-468. http://dx.doi.org/10.1016/j.ympev.2004.06.017

Shi, G., Grimaldi, D.A., Harlow, G.E., Wang, J., Wang, J., Wang, M., Lei, W., Li, Q. \& Li, X. (2012) Age constraint on Burmese amber based on $\mathrm{U}-\mathrm{Pb}$ dating of zircons. Cretaceous Research, 37, 155-63. http://dx.doi.org/10.1016/j.cretres.2012.03.014

Ward, P.S. (1994) Adetomyrma, an enigmatic new ant genus from Madagascar (Hymenoptera: Formicidae), and its implications for ant phylogeny. Systematic Entomology, 19, 159-175. http://dx.doi.org/10.1111/j.1365-3113.1994.tb00585.x

Ward, P.S. \& Brady, S.G. (2003) Phylogeny and biogeography of the ant subfamily Myrmeciinae (Hymenoptera: Formicidae). Invertebrate Systematics, 17, 361-386. http://dx.doi.org/10.1071/IS02046

Ward, P.S. (2007) Phylogeny, classification, and species-level taxonomy of ants (Hymenoptera: Formicidae). Zootaxa, 1668, 549-63.

Yamane, S., Bui, T.V. \& Eguchim K. (2008) Opamyrma hungvuong, a new genus and species of ant related to Apomyrma (Hymenoptera: Formicidae: Amblyoponinae). Zootaxa, 1767, 55-63.

Yoshimura, M., Fisher, B.L. (2012) A revision of male ants of the Malagasy Amblyoponinae (Hymenoptera: Formicidae) with resurrections of the genera Stigmatomma and Xymmer. PLOS ONE, 7(3), e33325. http://dx.doi.org/10.1371/journal.pone.0033325

Yek S.H., \& Mueller, U.G. (2011) The metapleural gland of ants. Biological Reviews, 86, 774-91. http://dx.doi.org/10.1111/j.1469-185X.2010.00170.x 